\title{
REVISIÓN/REVIEW
}

\section{CRUZANDO FRONTERAS: TODO SOBRE MI MADRE (1999) DE PEDRO ALMODÓVAR}

Isabel Maurer-Queipo ${ }^{1}$ : Universidad de Siegen. Alemania.

maurer@romanistik.uni-siegen.de

\section{RESUMEN}

El estudio presente sobre Todo sobre mi madre (1999) de Pedro Almodóvar se basa sobre todo en lo híbrido que caracteriza toda la obra del director español. Con este concepto de una estética de lo híbrido se muestra ilustrativamente la posición ambivalente del director español, sus combinaciones sensibles y sutiles de un pasado oscuro y un presente colorido, de diferentes elementos culturales nacionales e internacionales como sus homenajes a artistas latinoamericanos como Caetano Veloso, Chavela Vargas, Augustín Lara. También hay que añadir las vinculaciones de los géneros literales y cinematográficos y sobre todo sexuales - representados aquí magistralmente mediante el tema de la teatralidad.

PALABRAS ClAVE: Teatralidad - Intermedialidad - Performatividad - Hibridez Pedro Almodóvar

\section{CROSSING BORDERS: ALL ABOUT MY MOTHER (1999) BY PEDRO ALMODÓVAR}

\section{ABSTRACT}

The present article on Pedro Almodóvar's All About My Mother (1999) is based on the hybridity that characterises the director's whole work. The aesthetics of hybridity allows us to show the multifaceted positions of the director, his sensitive and subtle combinations of a dark past and a colourful present, of different national and international cultural elements like his homages to Latin American artists such as Caetano Veloso, Chavela Vargas, Agustín Lara. Furthermore we have to add the links

\footnotetext{
${ }^{1}$ Autor Correspondiente:

Isabel Maurer Queipo: Universidad de Siegen. Alemania

Correo: maurer@romanistik.uni-siegen.de
} 
to literary and filmic genres, and above all to sexual genders - masterly represented here by means of Almodóvar's sense of the theatre.

KEY WORDS: Sense of the theatre - Intermediality - Performance - Hybridity Pedro Almodóvar

\section{INTRODUCCIÓN}

En 2002, Hable con ella gana el Óscar por el mejor guion - lo que significa algo muy importante considerando la obra cinematográfica como multiartística. Es decir, que al contrario de un texto, la película se considera un producto de varias personas: el guionista, el director, el productor ejecutivo, los técnicos, el director escénico, el director de producción, el camarógrafo, etc. Pocas veces se involucra tanto un director de cine en la producción de su película como Pedro Almodóvar. De este modo, la película se convierte en una especie de hijo único del director: después de que Matador (1986) hubiera alcanzado fama nacional e internacional, apoyada por Televisión Española (TVE) y el Ministerio de Cultura, Almodóvar fundó con su hermano su propia empresa de producción, El Deseo. Se libró de la dependencia económica, pero sobre todo de la dependencia artística de las instituciones cinematográficas con la intención de ser padre único de sus hijos fílmicos. Almodóvar mismo declaró:

Avec mes cinq premiers films, j'ai l'impression d'avoir eu cinq enfants et inq pères différents et d'être toujours en litige avec chacun d'eux, d'autant que mes films leur appartiennent non seulement économiquement mais un peu aussi artistiquement, au niveau de leur conception. [Con mis cinco primeras películas he tenido la impresión de tener cinco hijos de cinco padres diferentes y de estar siempre en litigio con cada uno de ellos, sobre todo porque las películas les pertenecen no solo económicamente, sino también un poco artísticamente a nivel de su concepción]. (Seguin, 1995, p. 70)

En este sentido, se podría aplicar a la obra del director español el término de la caméra-stylo, creado a mediados del siglo veinte por Alexandre Astruc -aunque muchos críticos lo consideran pasado de moda, también a causa de los debates sobre la muerte del autor iniciados sobre todo por Roland Barthes (Barthes, 1994, p. 491495) y Michel Foucault (Foucault, 1969, p. 789-821).

Le cinéma est en train tout simplement de devenir un moyen d'expression, ce qu'ont été tous les autres arts avant lui, ce qu'ont été en particulier la peinture et le roman. Après avoir été successivement une attraction foraine, un divertissement analogue au théâtre de boulevard et un moyen de conserver les images de l'époque, il devient peu à peu un langage. Un langage, c'est-à-dire une forme dans laquelle et par laquelle un artiste peut exprimer sa pensée, aussi abstraite soit-elle, ou traduire ses obsessions exactement comme il en est 
aujourd'hui de l'essai et du roman. C'est pourquoi j'appelle ce nouvel âge du cinéma celui de la caméra-stylo. [El cine está convirtiéndose simple y llanamente en un medio de expresión, cosa que ya fueron antes las demás artes, y en particular, la pintura y la novela. Después de haber sido sucesivamente una atracción de feria, una diversión análoga al teatro de bulevar y un medio para conservar las imágenes de la época, se convierte poco a poco en lenguaje. Un lenguaje, o sea una forma en la cual y por la cual un artista puede expresar su pensamiento, por abstracto que sea, o traducir sus obsesiones exactamente como pasa hoy en día con el ensayo y la novela. Por eso denomino ese nuevo siglo del cine el de la cámara-pluma]. (Astruc, 1948, p. 144)

Aludiendo al mismo tiempo a las tesis de Marshall McLuhan (McLuhan, 1965) sobre los medios comunicativos como extensión del cuerpo, como prótesis artísticas, Almodóvar se inscribe en su obra. Expresando allí sus pensamientos, traduciendo sus obsesiones, realiza una combinación entre autobiografía, contexto histórico y obra. Pero las fronteras entre realidad y ficción, entre su vida y el cine no se disuelven. Es casi más que la idea de la camára como pluma del autor. Almodóvar va más allá de esta idea cuando retoma técnicas barrocas del engaño y desengaño dejándolas culminar en una reversión de la realidad y la ficción. Transforma el medio cinematográfico en espacio auténtico y real de sí mismo, mientras que la realidad funciona como construcción de su propia persona. En cuanto a La flor de mi secreto (1995) Almodóvar dijo:

Le cinéma est pour moi de plus en plus un moyen pour m'ouvrir, pour me montrer tel comme je suis pendant que je peux me cacher dans la vie, m'isoler, transmettre une image totalement construite de moi; j'ai le temps. Dans le cinéma, je dois être ce que je suis. Comme le processus d'ouverture s'est effectué partiellement de façon inconsciente, cette fois il était moins douloureux. [El cine es para mí cada vez más un medio para abrirme, para presentarme tal como soy, mientras que en la vida me puedo esconder, aislarme, transmitir una imagen mía totalmente construida: tengo tiempo. En el cine tengo que ser lo que soy. Como el proceso de apertura se efectúa parcialmente de manera inconsciente, esta vez no ha sido tan doloroso]. (Strauss, 1998, p. 200)

El mismo Almodóvar se convierte en protagonista espectral e invisible de su universo artístico.

\section{DESARROLLO}

\subsection{La estética de lo híbrido}

Este universo está construido a través de una estética de lo híbrido (Maurer Queipo 1995) que incluye, en resumen, los siguientes aspectos:

a) El uso de la intermedialidad en analogía al concepto de la intertextualidad de Julia Kristeva: es decir, la mezcla e integración de otros medios como pintura, fotografía, ópera, literatura, radio, televisión, anuncios, etc., pero también la 
b) La autorreferencialidad: es decir, la recurrencia a sus propias obras (aquí la alusión, por ejemplo, a La flor de mi secreto y a Todo sobre mi madre, 1999) manteniendo un hilo conductor de su obra completa;

c) La mezcla de géneros (el (melo)drama, la comedia, la tragedia, etc.)

d) La mezcla cultural entre tradición y modernidad (aquí, por ejemplo, la tauromaquia, lo folclórico, el teatro moderno);

e) La mezcla de géneros y sexos, es decir, el juego con las identidades y estereotipos, el travestismo y la transexualidad (aquí, por ejemplo, la androginidad de la corrida, la feminización de los protagonistas).

Con estas estrategias intermediales, sus recursos infinitos y fuentes inspirativas a nivel nacional (de Góngora a Valle-Inclán, Lorca y Buñuel) e internacional (de Ibsen a Mankievicz), su mezcla postmoderna de lo tradicional y lo moderno ${ }^{2}$, Almodóvar nos muestra una combinación original de un cine-teatro en donde ya no existe esa lucha antigua, esa competencia entre los dos medios. Nos presenta una sinergia creativa entre ambos que ha sustituido, por ejemplo, el simple teatro filmado, las adaptaciones de obras de teatro al cine $e^{3}$. En las obras recientes el lenguaje teatral y el lenguaje fílmico se entremezclan y crean nuevos tipos de géneros y medios que reflejan el espíritu lúdico del postfranquismo y el espíritu híbrido de la postmodernidad.

Finalmente, Pedro Almodóvar ha creado con Todo sobre mi madre (1999) un nuevo cine-teatro: el screwball-drama.

La idea principal de Pedro Almodóvar en cuanto a Todo sobre mi madre 4 fue "hacer una película sobre la capacidad de actuar de determinadas personas que no son actores". Almodóvar introduce con esta cita su tema principal: el teatro de la vida. Ya La flor de mi secreto (1995) empieza con un teatro, con un engaño visual del público: dos médicos intentan persuadir a una madre para que done los órganos de su hijo que está en coma. Es una situación de incomprensión, llena de lágrimas. Poco después todo se aclara. Se trata de una prueba, de una simulación, una simulación de una tragedia humana.

Cuatro años más tarde, Almodóvar repite «como forma de mise-en-abyme» la misma situación en Todo sobre mi madre.

La película imita la ficción, pero, poco después, la simulación se convierte en realidad para la protagonista Manuela, que Almódovar describe como "mujer normal, que en

\footnotetext{
${ }^{2}$ Para más información sobre la obra de Almodóvar, véase entre otros Maurer Queipo, 2005.

3 Sobre todo Franz-Josef Albersmeier, Jürgen Müller, Beate Ochsner, Joachim Paech, Irina Rajewsky, Volker Roloff, Peter Zima han investigado sobre el fenómeno de la intermedialidad, de la relación entre los medios de comunicación.

${ }^{4}$ En el resto del artículo las referencias a Todo sobre mi madre serán abreviadas, denominándose (M).
} 
las simulaciones [...] se convertía en auténtica actriz, mucho mejor que los médicos con los que compartía la escena" (texto del DVD).

Ahora quieren realmente que Manuela done el corazón de su hijo único, Esteban, que ha tenido un accidente de tráfico después de visitar una obra de teatro. De este modo, en pocos instantes, el órgano tendrá un dueño nuevo. No solamente en caso de muerte y de donación de órganos sino también en muchos otros casos, como el de la cirugía plástica, el cuerpo humano funciona como depósito humano de piezas de repuesto. Al espectador de Todo sobre mi madre se le presentará este fenómeno grotesco y teatral en diferentes escenas y variaciones. La ficción en esta película se convierte en realidad trágica y así se muestra lo teatral de la vida entre tragedia y comedia, entre screwball drama y screwball comedy.

Pedro Almodóvar: Si existiera el término (sólo se adjudica a la comedia delirante, me refiero a la 'screwball comedy'podríamos definir Todo sobre mi madre como un 'screwball drama'. Drama disparatado, barroco y con personajes extremos, vapuleados por el azar (sin que sea gran guiñol, o drama grotesco)." (Texto del DVD)

A primera vista, la vida aparece también como escenario calderoniano de la vida, como el clásico teatrum mundi. Según Pedro Calderón de la Barca en El gran teatro del mundo y su famoso dogma del obrar bien, cada uno debe desempeñar su papel dado por Dios- de la mejor manera posible. En lo siguiente, Almodóvar nos presentará, con su screwball drama, otras variantes contrarias, otros escenarios, en donde cada uno puede escoger su rol preferido. Nadie parece estar limitado a un solo papel. Al mismo tiempo, esto convierte la idea calderoniana del libre albedrío en un esquema verdaderamente libre.

Manuela viaja a Barcelona en busca del corazón de su hijo ${ }^{5}$, de la persona a la que han donado el corazón, y también del padre de éste, Esteban (senior). Allí encuentra a la siguiente figura de esta obra de cine-teatro tan enredada y polivalente: su antigua amiga Agrado. Antes, cuando todavía era hombre, había sido camionero - o había tenido el papel de camionero. Ahora se ha convertido en prostituta o desempeña este papel con la ayuda de algunos requisitos y prótesis femeninas ${ }^{6}$.

Es sarcásticamente Agrado quien reprocha a los drags y travestis que confunden travestismo con circo y teatro aunque ella misma dice que por la parte de arriba es neumática refiriéndose a sus pechos artificiales. Con esto confirma la mezcla irónica

\footnotetext{
5 Esta búsqueda tiene su paralelo más tarde en la entrada en escena de Blanche Dubois (la protagonista de la obra de teatro A Streetcar Named Desire de Tennessee Williams), durante la cual busca desesperadamente su caja de joyas en forma de corazón. Así aquí los paralelismos de los destinos de las mujeres se hacen más que evidentes.

${ }^{6}$ También los intentos acríbicos de Tina, la protagonista de La ley del deseo (1986), de representar a una mujer perfecta y completa, llevan más bien a una hiperrealización y artificialidad dominantes en la película y subrayadas por escenarios que aluden a las obras de Edward Hopper (cf. Maurer Queipo, 2005). I gualmente el padre de Esteban, Esteban senior, se ha perfeccionado, femenizado quirúrgicamente (junto con Agrado) y se ha convertido en Lola, La pionera.
} 
de cirugía plástica y taller mecánico, de artificialidad y normalidad. Al igual que se hinchan ruedas, se inflan neumáticamente las partes del cuerpo. El arte de disfrazarse se muestra así como simple teatro mecánico: incluso un par de tetas del cuarto de aderezos de un escenario mundial o un traje (imitado) de Chanel crean nuevos personajes e identidades ${ }^{7}$.

\subsection{Carnaval textil}

En este juego de autenticidad y ficción, Agrado hace además uso de los sectores clásicos de la moda para poner de relieve visual y materialmente el modelo del travestí y del cross-dressing. Al mismo tiempo, critica y ridiculiza el fetichismo por las marcas de nuestra sociedad de consumo8. Ya desde hace mucho tiempo el sector de la moda prefiere la estética, el arte del engaño visual, más que la función práctica (como medio de vestir). La ropa se ha liberado de su rol protector a favor de una moda que determina el respeto y el grado de aceptación de una persona: "No hay nada como un chanel para sentirse respetable..." (M).

Por otra parte, con la ropa ligera y disparatada de Manuela, Almodóvar recurre a un carnaval textil ya celebrado por las majas y majos españoles de antaño que se manifiesta en un efecto trickle-down: como parte del ocio, las clases altas se habían adueñado del código textil de las clases bajas para adaptar legítimamente no sólo los signos exteriores, sino también sus comportamientos frívolo-burlescos9. Así, los códigos textiles actuales manifiestan su rol importante y polivalente, muchas veces subestimado, en cuanto a los disfraces de las clases sociales y de los géneros sexuales.

Mientras que la red de relaciones se amplía, Almodóvar presenta cada vez más facetas de lo teatral. Después de haber golpeado a Agrado, ella se queja de su apariencia: “¿Un poco hinchada?... ¿Pero dónde voy yo con este careto? ¡No encajo en ningún tipo de perversión! Bueno, necrofilia o bestialismo, tal vez..." (M).

Almodóvar es capaz de desenmascarar esas desfiguraciones y deformaciones de la vida cotidiana, lo dudoso de las convenciones y de nuestra sociedad con la ayuda de un repertorio esperpéntico - recurriendo a los procedimientos grotescos (españoles) de Francisco de Goya para demostrar lo absurdo de la vida humana y a las formas de representación estéticas de Francisco de Quevedo y de Ramón María del Valle-

\footnotetext{
${ }^{7}$ Como muestra Virginia Woolf en su famoso Orlando (1928), la apropiación de la ropa, la mímica, los gestos, los códigos de los gestos y del vestimentario sobre todo de una persona de otro rango y sexo son de gran importancia para la presentación (teatral) de sex y gender. De esta forma sex y gender se revelan al mismo tiempo como elementos de escenificación y efectos de los códigos sexuales. Cf. también Schößler, 1998.

${ }^{8}$ En otra escena Huma Rojo lleva una capa de Sybilla - un guiño a la gran modista de la Movida Madrileña y al mismo tiempo un homenaje a Gena Rowland en Opening Night de John Cassavetes (1977). Sobre los fenómenos del cross-dressing y máscaradas, véase Penkwitt y Pusse, 1998.

${ }^{9}$ Con la imagen de "la grand dame jugando el papel de cocotte" Barbara Vinken (1998) describe en su estudio la relación entre moda y aristocracia, feminidad y engaño.
} 
Inclán ${ }^{10}$. Pone estas convenciones en cuestión y remite a las determinantes patriarcales de la sociedad. Agrado subraya en esta escena el corsé de las condiciones sociales y al mismo tiempo la obligación del dictado de la moda, que actualmente ha superado todas las fronteras (plástica-sintéticas). Ella sostiene explícitamente que lo malo de su profesión es que hay que estar elegante de todas las formas y " $\mathrm{isiempre}$ al loro de los últimos avances tecnológicos en cirugía y cosmética!" (M). Agrado misma llevará esta locura de presión social en el sector de la cirugía plástica a su punto culminante con un monólogo agudo en el escenario del teatro Tívoli, al final de la película.

\subsection{Teatro visual y oral}

Madre: "NNo me gusta que una extraña me vea falsificando chagales!" (M)

Es el mundo del glamour, de las estrellas de cine y de los medios de comunicación que se presentan bajo el signo del engaño. Igualmente, la burguesía sigue un engaño visual que está combinado con una esquizofrenia consciente - la separación entre la esfera pública y privada - siguiendo el dogma del Siglo de Oro español según el cual la opinión pública dominaba la vida cotidiana: detrás de su fachada burguesa, la madre de la monja Hermana Rosa se presenta como falsificadora de obras de arte, especializada en Chagalles (Fig. 1) ${ }^{11}$ y Picassos (Fig. 2).

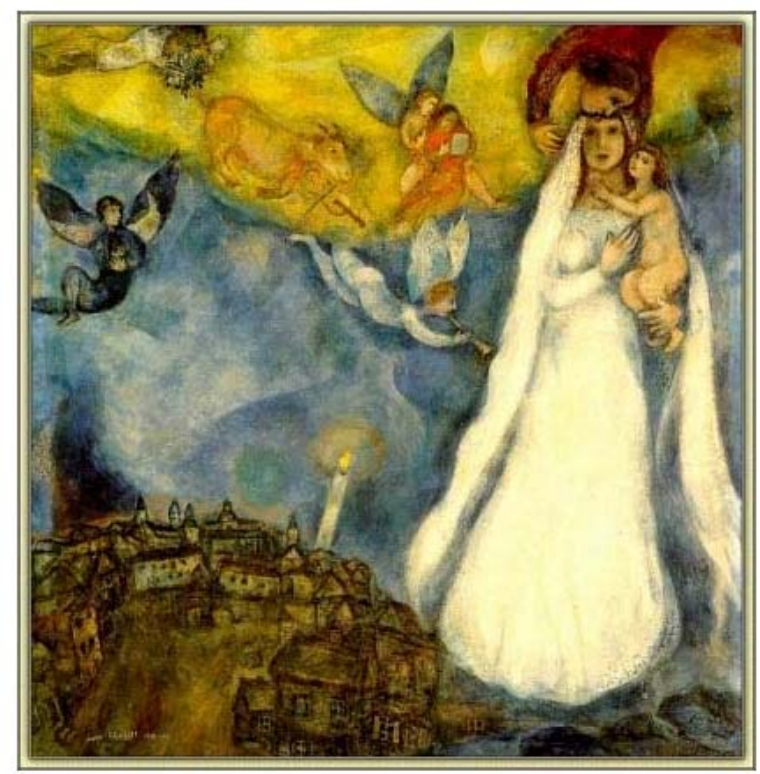

Figura 1. Marc Chagall, La Madonna du village (1938-1942)

\footnotetext{
${ }^{10}$ Aquí se deberán mencionar sobre todo La vida del Buscón (1626) de Quevedo, los Caprichos (1799) de Goya, y Luces de bohemia (1920) de Valle-Inclán.

${ }^{11}$ Aquí, por ejemplo, se recurre irónicamente a la obra de Marc Chagall La Madonna du village (19381942), que visualiza elementos, escenarios, figuras diferentes de la película como la maternidad (sin padre), el rol de Rosa y la virginidad virtuosa.
} 


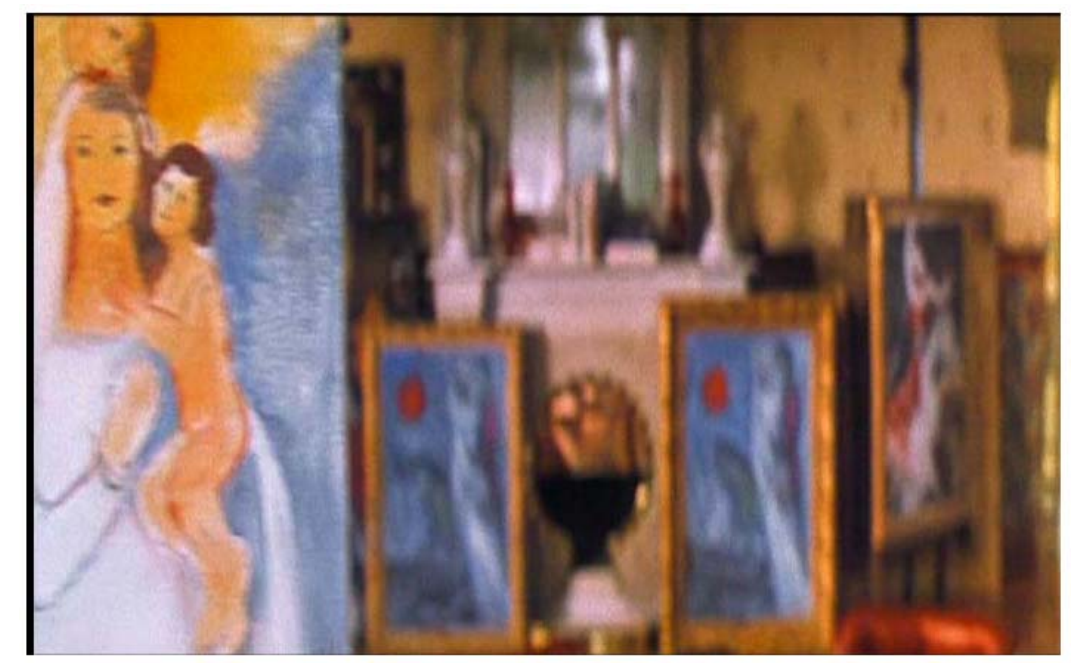

Figura 2. Imagen de Todo sobre mi madre.

Y hay que añadir que la Hermana Rosa es embarazada por el travesti Lola (Esteban senior), quien a su vez la ha contagiada de sida, lo que significa otra ruptura inaudita de las convenciones sociales.

Al teatro de las mascaradas visuales y materiales dominantes en la película, se unen el teatro oral, las falsificaciones orales, el disfraz de la palabra. Para Almodóvar, el arte de mentir ya no es esa mentira que, durante la dictadura de Francisco Franco, se declaraba pecado mortal en combinación con una constante mala conciencia, con un control y una censura de los pensamientos que dominaba la vida cotidiana de la sociedad. Para él, la mentira se ha convertido en un sistema de protección, en un instrumento diplomático para evitar las tragedias tal como lo había conocido en su infancia, para "perfeccionar la realidad, añadiéndole un poco de ficción":

Yo a veces vigilaba lo que mi madre leía y comprobaba con estupor que no coincidía con el contenido de la carta. Por ejemplo mi madre leía (interpretaba más bien) "y muchos besos para la abuela, que me acuerdo mucho de ella. Las ganas que tengo de sentarme en el patio, con una palangana de agua para peinarla y hacerle su moño como a ella le gusta." En la carta por ejemplo, no aparecía ninguna referencia a la abuela. De vuelta a casa, yo la recriminaba por inventarse parte del contenido de las cartas (en realidad no se lo inventaba, ella conocía a los personajes y sabía lo que querían oír). Mi madre se defendía diciéndome: "ipero has visto la ilusión que le ha hecho a la abuela oír que su nieta se acordaba de ella!" (Almodóvar, 2000, p. 20)

La mentira no sigue siendo algo negativo del todo. Ahora puede verse en el escenario de la vida cotidiana como algo positivo que ya no sirve como atributo de los pecadores. Se ha convertido en un aspecto básico de la vida. Finalmente se disuelve la dicotomía entre verdad y mentira. 
De tal manera, imitación, disimulación y mentira se integran también en la vida de la protagonista Manuela. Los seminarios de donación de órganos han sido dominados por la simulación y la improvisación - características que ya no son privilegio del arte de hacer teatro sino de lo cotidiano. Huma: “¿Pero tú sabes actuar?". Manuela: "Sé mentir muy bien y estoy acostumbrada a improvisar" (M).

Otra de las escenas polivalentes y de gran importancia se manifiesta cuando Agrado realiza su actuación, mencionada anteriormente. Ahora la autenticidad se revela como una envoltura vacía, como puro simulacro. El cuerpo humano, del que se cree que es auténtico, se convierte en prótesis técnicamente reproducible, en objeto expuesto sintético:

Agrado: Me llaman la Agrado porque toda mi vida sólo he pretendido hacerle la vida agradable a los demás. [...] Además de agradable, soy muy auténtica. ¡Miren qué cuerpo! ¡Reparen! ¡Todo hecho a medida! Rasgado de ojos, ochenta mil. Nariz, doscientas, tiradas a la basura porque un año después me la hicieron así de otro palizón. Ya sé que me da mucha personalidad, pero si llego a saberlo no me la toco... Continúo: Tetas, dos. Setenta cada una, pero estás las tengo ya súper amortizadas. Silicona en labio, frente, pómulo, cadera y culo. El litro cuesta cien mil, así que echad la cuenta porque yo ya la he perdido. Limadura de mandíbula, setenta y cinco mil. Depilación definitiva con láser, porque la mujer también viene del mono, tanto o más que el hombre, setenta mil por sesión. Depende de lo barbuda que seas, lo normal es de dos a cuatro sesiones, pero si eres folclórica necesitas más, claro. Lo que les estaba diciendo, ¡cuesta mucho ser auténtica! Pero no hay que ser tacaña con nuestra aparencia. Una es más auténtica cuando más se parece a lo que ha soñado de sí misma. (M)

Esta entrada en escena subraya al mismo tiempo la tesis famosa de Judith Butler de la performatividad $^{12}$, que acentúa la constructividad del género socio-cultural (gender) al igual que el género biológico (sex). Sex y gender se consideran como constructos independientes el uno del otro, como artificios que flotan libremente - "freefloating artifice" (Butler, 1990, p. 6). Así, las performances, los juegos de autenticidad y artificialidad tienen lugar en los mencionados niveles visuales, corporales y lingüísticos y son afirmados además con la ayuda de recursos intermediales. Finalmente lo teatral confirma una vez más su posición definitiva en la vida cotidiana.

\subsection{El teatro (inter)nacional como fuente de inspiración y recursos intermediales}

Una de las aptitudes creativas del director manchego es abrir diferentes niveles fílmicos y culturales para un público nacional e internacional que no necesita conocer por ejemplo los códigos de las tradiciones españolas. Dedicarse a descifrar el tesoro de citas se revela siempre como un proyecto enormemente cautivador en el juego de

\footnotetext{
${ }^{12}$ Sobre la performatividad destacan las obras de Erika Fischer-Lichte y Christoph Wulf.
} 
comunicación entre el autor y su receptor creando así cada vez una obra diferente. También las obras de teatro en cada actuación son distintas y dinámicas, a diferencia del cine invariable y estático.

Como hemos visto, en esta película Almodóvar confronta a su público con diferentes formas de teatro y de teatralidad: el propio título Todo sobre mi madre (en inglés All About My Mother) se refiere a la obra de teatro All About Eve1 ${ }^{13}$ (1950) del autor americano J oseph Leo Mankievicz.

Al principio, se presenta una escena de la adaptación fílmica con la protagonista Bette Davis como Margot Channings que Manuela y su hijo Esteban (júnior) están viendo en la televisión (Fig. 3 y Fig. 4).

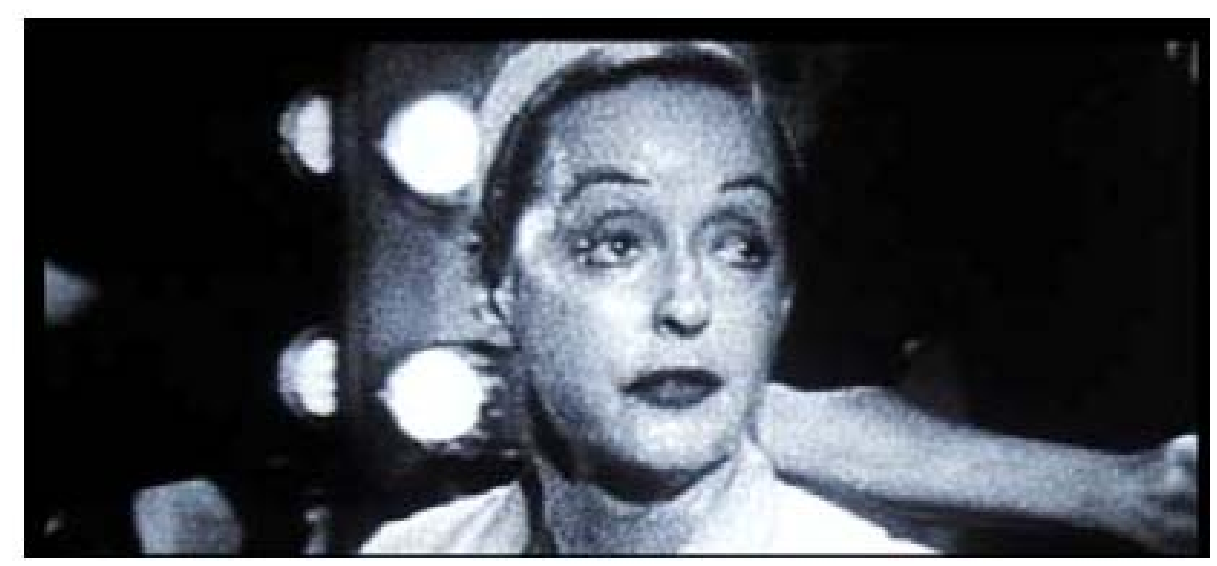

Figura 3. Imagen de Todo sobre mi madre, Bette David.

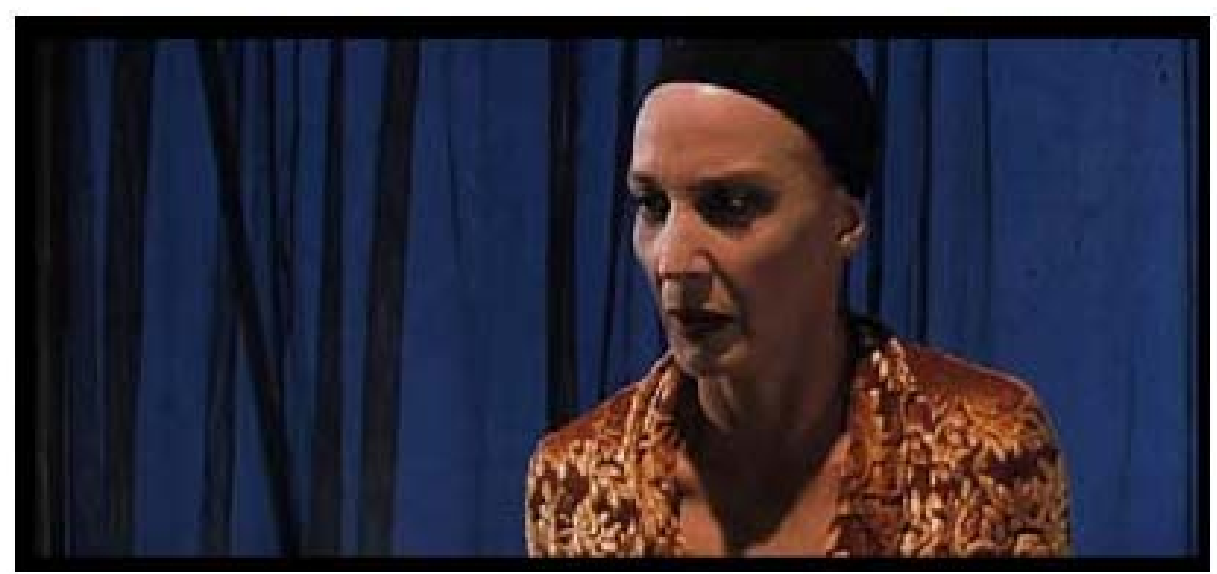

Figura 3. Imagen de Todo sobre mi madre, Marisa Paredes como Huma Rojo.

Además, All About Eve sirve a Esteban como base para su propio libro Todo sobre mi madre (All About Mom). Cuando Manuela le regala a su hijo el libro Music for Chameleons (1980) de Truman Capote en su cumpleaños amplía la red de citas y subraya al mismo tiempo las paralelismos entre Esteban y Capote: la soledad

\footnotetext{
${ }^{13}$ Lo interesante es que en sus tiempos la película fue prohibida en el festival de cine de San Sebastián -lo que subraya el placer de Almodóvar por lo inconvencional-.
} 
existencial o las fugas fantásticas de los jóvenes y marginalizados. Como además los dos han empezado muy pronto a escribir se trata de un juego intermedial. Los dos se pueden considerar como alter ego de Almodóvar mismo que tematiza de esta manera su profesión de escritor.

En la noche del cumpleaños de Esteban empieza un juego, una obra de teatro en la que cada medio de comunicación se refiere a otro. Las historias de los protagonistas se entremezclan, se varían y se actualizan. La escena de All About Eve que están viendo Manuela y Esteban en la televisión tiene lugar en el camerino de la gran actriz Margot Channings (representada por Bette Davis) con la entrada en escena de Eve Harrington. Esta última se presenta primero como aficionada de Channings, pero más tarde se convierte en actriz sin escrúpulos, insidiosa y falsa. Esta metamorfosis, esta hipocresía, se repite más tarde como mise-en-abyme, como un juego de muñecas rusas. La escena cambia cuando Esteban (júnior) intenta obtener un autógrafo de la protagonista Huma Rojo, es atropellado por un coche y muere. Esteban, al igual que a primera vista Eve Harrington, pertenecía a esos fans del teatro que sentían una profunda fascinación por el teatro y los actores y no a la especie de caza-autógrafos que Margot Channing había degradado como inútiles, porque no tenían interés ni en la obra ni en las personas.

Aparte de su burla melodramática del espectáculo medial, su mundo de intrigas y de decadencia, del sueño y de la ilusión, la obra de Mankievicz All About Eve presenta una actitud sociocrítica que años después, en la obra de Almodóvar, no ha perdido ni su poder ni su actualidad. También la historia de Nina y Manuela se refiere al texto americano. Esta vez, Manuela obtiene el rol de Eva (la hipócrita, la mala) y Nina el rol de Margot (la buena). Sin embargo la expectativa del público, influida por el original americano, de que Manuela - al igual que una Eve Harrington - podría quitarle el rol a Nina, no se cumple.

En esta escena, Almodóvar rompe finamente con el original, ya que su protagonista Manuela se presenta como anti-Eva Harrington porque se sabía el texto de Nina, no debido a que había planeado de antemano como la Eve de All About Eve, sino por experiencia e interés auténtico por el rol a causa de su pasado como actriz.

Un poco después, este escenario se repite de nuevo - como si se tratase de pruebas para una misma obra de teatro. I rónicamente esta vez es Agrado quien escucha en el camerino la obra por los altavoces y al final, también se sabe el texto de memoria ${ }^{14}$.

En otra ocasión, Manuela tiene que sustituir a Nina en una obra de teatro (A Streetcar Named Desire de Tennessee Williams, 1947) presenta el papel de la protagonista Stella y, al mismo tiempo, a sí misma: sus lágrimas, su dolor y su tristeza por el hijo perdido estallan en el escenario. De este modo, con la interpretación no profesional de Manuela, la obra parece ser mucho más auténtica y se convierte en un éxito para el público. De esta manera se lleva la vida al escenario y se teatraliza. Las premisas de

14 Con un guiño, Almodóvar alude al mismo tiempo con esta escena de sincronización, autorreflexivamente, a las técnicas fílmicas, al arte teatral de hacer películas. 
imitatio y mimesis se ponen una vez más de relieve aludiendo a otra de las obras clásicas de la literatura mundial: Don Quijote de la Mancha.

\subsection{Traumatismo quijotesco}

Como se sabe, a causa de su lectura fanática (sobre todo de los libros de caballería), el protagonista de la famosa obra de Miguel de Cervantes ya no podía distinguir entre la realidad de las historias leídas y su propia realidad; de tal manera que un día se denominó él mismo caballero Don Quijote de la Mancha y salió a conquistar el mundo:

En resolución, él se enfrascó tanto en su lectura, que se le pasaban las noches leyendo de claro en claro, y los días de turbio en turbio, y así del poco dormir y del mucho leer, se le secó el cerebro, de manera que vino a perder el juicio. Llenósele la fantasía de todo aquello que leía en los libros, así de encantamiento, como de pendencias, batallas, desafíos, heridas, requiebros, amores, tormentas y disparates imposibles, y asentósele de tal modo en la imaginación que era verdad toda aquella máquina de aquellas soñadas invenciones que leía, que para él no había otra historia más cierta en el mundo. (Cervantes, 2005, p. 37-38)

A causa de una especie de traumatismo quijotesco de tanto leer ${ }^{15}$, Nina, paralelamente, se convierte en víctima del arte de hacer teatro: también ella empieza a confundir el texto con su propia realidad, al no poder distinguir entre Manuela y su rol como Eva Harrington de All About Eve. Al mismo tiempo se funde en su rol de Stella (la figura principal de la obra de teatro $A$ Streetcar Named Desire).

Mientras que All About Eve funciona como mise-en-abyme de diferentes aspectos del argumento fílmico - desesperación, locura, ansia, desamparo, soledad, decepción esto se refuerza en la película por la integración de la obra de teatro $A$ Streetcar Named Desire, en donde tanto domina la luz azul que convierte la obra en análoga al sueño. Esperanzas y deseos se convierten en sueños universales, se clasifican como función clave de la vida que acompaña a la película como hilo conductor.

En el sentido del traumatismo quijotesco, también aquí se mezclan el arte de hacer teatro y la realidad, la vida se hace ficción cuando cada participante se adueña de su parte de los pretextos mediales: "Huma triunfa en el escenario cuando vive el drama de Blanche Dubois y fracasa cuando vive su propio drama" (texto del DVD) 16. Literalmente, Huma dirige su texto como Blanche Dubois (la protagonista de A Streetcar Named Desire) a Manuela, fuera del escenario. Es una de las frases principales, un hilo conductor de la película. Blanche/Huma: "Gracias. Quienquiera que seas, siempre he confiado en la bondad de los desconocidos" (M).

\footnotetext{
${ }^{15}$ En el siglo XIX, también el bovarismo en la famosa obra de Gustave Flaubert Madame Bovary (1857) presenta un traumatismo quijotesco. Por su lectura de novelas amorosas, Emma Bovary se sumerge en un mundo romántico confundiendo realidad y ficción. Sobre el fenómeno del bovarismo, véase Gaulthier, 2006.
} 
Por el contrario, en la obra de Williams la bondad de los desconocidos no lleva a ningún final feliz - Blanche, violada por su suegro, no recibe ninguna ayuda de su hermana y será internada en una clínica psiquiátrica. Entre los desconocidos, entre los protagonistas de la película almodovariana se crean redes de relaciones muy solidarias e íntimas, hasta (homo)eróticas. Almodóvar subraya el aspecto andrógino, la teatralidad de relaciones (homo)eróticas en las que, como ya hemos mencionado, las parejas pueden escoger libremente su rol - liberándose del pensamiento rígido de los roles clásicos patriarcales.

Almodóvar se sirve del potencial emancipatorio de Williams cuando la protagonista Stella se libera de su prisión casera, de su casita de muñecas17. Ella abandona a Stanley con el bebé recién nacido - tal como Manuela se había separado de Lola/Esteban antes del nacimiento de Esteban (junior).

Una vez más trasluce la crítica social -inspirada en esta referencia intermedial-. La crítica de Williams de la sociedad (americana) se muestra en la insistencia penetrante de Stanley en el código napoleónico -el derecho de ambos cónyuges a los bienes de su pareja- y al mismo tiempo en varios detalles, aparentemente sin importancia, como la entrada irónica en escena de los vendedores ambulantes que ofrecen plátanos y perritos calientes. Ya en la obra de Williams se subraya la dominancia del ser y el parecer, de la verdad y la mentira que se manifiestan paradigmáticamente también aquí en los signos visuales del vestuario glamouroso/extravagante de Blanche. A primera vista, no se podría distinguir si se trata de un collar de diamantes o de una imitación, si se trata de un abrigo de visón o de una imitación barata. Las figuras de la obra, la expresada "animosidad natural entre los sexos", los sentimientos de las mujeres, la tematización crítica de los valores materiales e inmateriales se convierten también en decorado móvil del director español que lo varía y actualiza en nuevos contextos.

\subsection{Pretextos intermediales}

Aparte de estos elementos intercalados, implícitos y explícitos, de citas teatrales, Almodóvar amplía su repertorio de pretextos intermediales que se distinguen a veces solamente por frases cortas de las protagonistas. Cuando Agrado entra en el piso de Manuela cita la película How To Marry A Millionaire de Jean Negulesco (1953) - la que por el protagonismo de Marilyn Monroe ha tenido tanto éxito - y formula así un homenaje al arte de hacer teatro y a la amistad femenina. Agrado: "Pero bueno, iqué sorpresa! Tres chicas solas, en una casa con pocos muebles siempre me recuerda cómo casarse con un millionario" (M).

Este repertorio de citas, que refuerza y prepara el coup de teatro al final de la película, se amplía también a través de un componente mitológico. Así, Esteban (Lola) aparece como visión mórbida en el entierro de Rosa, que finalmente ha muerto de sida. A través de un guiño surrealista, Almodóvar alude a su modelo español, Luis Buñuel, e irrita al público versado mostrando una mosca en la cara de Lola. Las moscas en la cara del señor de la casa en el film L'âge d'or (Buñuel, 1930) provocan sonrisas y al 
mismo tiempo incomodidad e irritación, ya que siempre se busca un sentido - aquí sin éxito.

Como en este caso, lo cotidiano se revela como trampa (surrealista) tal como lo declara Michael Schwarze cuando se pregunta ¿por qué nos irrita tanto una mosca en un vaso de vino en una película de Buñuel (Schwarze, 1993, p. 115.)? Y constata que lo cotidiano combinado de manera extraña (surreal) irrita más al espectador que lo extravagante que coincide con nuestras expectativas ${ }^{16}$.

Este detalle de la mosca nos hace pensar también en la conocida obra de teatro Les Mouches (1943) de Jean Paul Sartre. Esta obra se basa en el mito de la Orestía y también constituye, con un sentimiento de angustia, el momento de la tragedia en la película de Almodóvar.

La entrada en escena de un hombre (Esteban/Lola senior) que ha abandonado a su mujer y ha embarazado a una monja que muere por su culpa debería provocar la venganza de las furias mitológicas representadas en la obra de Sartre por las moscas: símbolos de la mala conciencia. Pero también aquí, Almodóvar rompe con su fuente de inspiración, ya que nadie se venga de otros y los roles no se pueden definir claramente: Lola no es ni hombre ni mujer y la forma tradicional de la familia visualizada en la película por la obra maestra arquitectónica de Antonio Gaudí La Sagrada Familia- ha sido sustituida por otras variantes y concepciones de relaciones humanas entre Manuela, Lola, Agrado, Rosa, etc. ${ }^{17}$

Al mismo tiempo, Almodóvar se sirve de estos elementos que desestabilizan las formas clásicas de mirar y pensar y une lo habitual con lo extravagante, la autenticidad con la artificialidad, la realidad y la ficción. Para Almodóvar la vida misma es ficción que -según las descripciones de su niñez y de su juventud grotescoesperpéntica- se parece a una obra de teatro surreal:

Ficción para mí era el mundo del patio, las vecinas, mis hermanas recibiendo clases de costura con sus amigas, los gatos, las matanzas, los gitanos, los cantaores que venían en la feria, el twist, colgar un conejo despellejado, todavía sangrante, bajo la parra; mi madre hablando con las vecinas en la puerta de la calle, al fresco de las largas noches de verano... y la gran pantalla del cine al aire libre. Un grueso muro, único fetiche al que me mantengo fiel. Detrás del muro pintado de blanco, los chicos hacíamos nuestras necesidades. Mito y fisiología, yo

\footnotetext{
${ }^{16}$ Schwarze también se pregunta por qué nos resulta chocante la escena de una trampa de ratones en otra película de Buñuel. Y explica que nos choca lo que no corresponde a nuestra experiencia. La trampa de ratones en un restaurante noble nos parece más absurdo que un coche estallando en las calles de México.

17 Manuela obtiene al mismo tiempo el rol de compañera y de madre y lo desempeña con más autenticidad que la madre biológica. También aquí las separaciones convencionales entre biología aparentemente incambiable y performatividad se ponen en cuestión. La maternidad ya no depende de la procreatividad: otra variante sería Esteban/Lola, la mujer que es introducida como padre del bebé. El concepto rígido de la familia sagrada, la heterosexualidad (obligatoria) y la procreación se disuelven a favor de otras formas (homo) sexuales, otras relaciones de amor.
} 
no lo sabía pero estaba aprendiendo muy pronto lo esencial. (Almodóvar, 2000, p. 18)

\section{CONCLUSIÓN}

La última alusión al teatro que Almodóvar integra con su placer barroco de combinar es un homenaje a Federico García Lorca - una de las figuras trágicas de la historia de la represión española. Con Haciendo Lorca de Lluis Pascal, que se ha inspirado en las obras de Lorca Bodas de sangre y Yerma y que además se estrenó en 1996 en el famoso teatro María Guerrero ${ }^{18}$, Almodóvar cierra su corro teatral. La madre que llora la muerte de su hijo - otra alusión al destino de Manuela - es además interpretada por Huma Rojo:

Huma: "Una fuente que corre durante un minuto y a nosotras nos ha costado años. Cuando yo descubrí a mi hijo, estaba tumbado en la mitad de la calle. Me mojé las manos de sangre y me las lamí con la lengua. Porque era mía. Los animales los lamen, ¿verdad? A mí no me da asco de mi hijo. Tú no sabes lo que es eso. En una custodia de cristal y topacios pondría yo la tierra empapada por su sangre..." (M)

En las pancartas de la obra dice: "Haciendo Lorca -Homenaje a García Lorca-, y a Esteban, un joven que murió a las puertas de un teatro, una noche de tormenta" (M).

A causa de la muerte al principio de la película, y debido a este homenaje a las mujeres y al teatro de la vida, se forma finalmente el marco de la película teatral almodovariana. Cuando al final cae el telón aparece el eslogan de la película: cada una de las figuras aparece - de manera similar a la estética onírica ${ }^{19}$ - como director, dramaturgo, creador de su propio drama:

A Bette Davis, Gena Rowland, Romy Schneider... A todas las actrices que han hecho de actrices. A todas las mujeres que actúan. A los hombres que actúan y se convierten en mujeres. A todas las personas que quieren ser madres. A mi madre. ${ }^{20}(\mathrm{M})$

Finalmente, Almodóvar representa, con su estética de lo híbrido, sus temas universales y especiales, su constante crítica sutil contra las injusticias sociales, contra

\footnotetext{
${ }^{18}$ María Guerrero fue una de las actrices, directoras de teatro y musa de grandes dramaturgos como Jacinto Benavente, Eduardo Marquina, los hermanos Quintero y Ortega Munilla. En su tiempo renovó el arte de hacer teatro y dio un nuevo giro al teatro que se hacía en ese momento.

19 "El alma humana, cuando sueña, desembarazada del cuerpo, es a la vez el teatro, los actores y el auditorio" (Borges, 1976, p. 9). También Elisabeth Lenk (1983) compara el sueño con el teatro.

${ }^{20}$ Gena Rowland interpreta el papel de una actriz de teatro en Opening Night (J ohn Cassavetes, 1977) que es testigo de la muerte trágica de una aficionada femenina, Bette Davis interpreta a la estrella caída por culpa de una actriz joven y corrupta en All About Eve (J oseph Leo Mankievicz, 1950) y Romy Schneider interpreta en $L^{\prime}$ important $C^{\prime}$ est $d^{\prime}$ aimer (Andrzej Zulawski, 1974) a una actriz sin éxito que sobrevive con su marido gracias a papeles en películas pornográficas baratas.
} 
las reglas establecidas, una forma de cine lúdico y también comprometido como el que plantea el cine actual español. Invita a sus espectadores a entrar en su universo fílmico, entre pasado y presente, modernidad y tradición, presentando mitos antiguos con nuevos medios y mezclándolos con la actualidad, subvirtiendo tradiciones rígidas con conceptos tolerantes de la igualdad de sexos.

\section{REFERENCIAS}

Almodóvar-Caballero, P. (2000). Discurso de Investidura como doctor honoris causa por la Universidad de Castilla-La Mancha.

Astruc, A. (1948). Naissance d'une nouvelle avantgarde: la caméra-stylo, en Revista L'Ecran Français.

Barthes, R (1994). Oeuvres complètes, vol. 2, 1966-1973. París: Éditions du Seuil.

Borges, J. L. (1976). Libro de sueños. Madrid: Torres Agüero.

Butler, J. (1990). Gender Trouble. Feminism and the Subversion of Identity. Londres: Routledge.

Butler, J. (1993). Bodies that matter On the Discursive Limits of "Sex". Londres: Routledge.

Capote, T. (1981). Music for Chameleons. Londres: Hamilton.

Cervantes-Saavedra, M. (2005). Don Quijote de la Mancha. Madrid: Anaya.

Flaubert, G. (1986). Madame Bovary. París: Flammarion.

Foucault, M. (1994). Dits et Écrits. París: Gallimard.

Gaulthier, J. (2006). Le Bovarysme. La psychologie dans l'oeuvre de Flaubert. París: PUPS.

Lenk, E. (1983). Die unbewußte Gesellschaft. Munich: Matthes \& Seitz.

Lommel, M.; Maurer Queipo, I. \& Rißler-Pipka, N. (eds.) (2004). Theater und Schaulust im aktuellen Film. Bielefeld: Transkript.

Maurer-Queipo, I. (2005). Die Ästhetik des Zwitters im filmischen Werk von Pedro Almodóvar. Frankfurt: Intermediale, kulturelle und genderspezifische Untersuchungen.

Mcluhan, M. (1965). Understanding Media. The Extensions of Men. Nueva York: McGraw- Hill. 
Penwitt, M. \& Pusse, T. K. (eds.) (1998). Cross Dressing und Maskerade, en Revista Freiburger FrauenStudien, Vol. 2, no 4, p. 9-15.

Quevedo-y-Villegas, F. G. (1993). La vida del Buscón. Barcelona: Crítica.

Sartre, J. P. (1969). Les Mouches. París: Gallimard.

Schößler, F. (1998). Als sie ein Knabe war' - Cross-dressing und Poetik in Goethes Wilhelm Meisters Lehrjahre und Woolfs Orlando, en Revista Freiburger FrauenStudien, Vol. 2, no 4, p. 61-74.

Schwarze, M. (1993). Buñuel. Reinbek bei Hamburg: Rowohlt.

Seguin, J. C. (1995): La Flor d'Almodóvar, en Revista L'Avant-Scène Cinéma, no 10, p. 70.

Valle-Inclán, R. M. (1993). Luces de Bohemia. Madrid: Espasa-Calpe.

Vinken, B. (1998). Frau als Mann als Frau: Mode als cross-dressing. Revista Freiburger FrauenStudien, 2(4): 75-90.

Williams, T. (2003). A Streetcar Named Desire. Harlow: Longman.

Woolf, V. (1970). Orlando. Londres: Hogarth Press. 